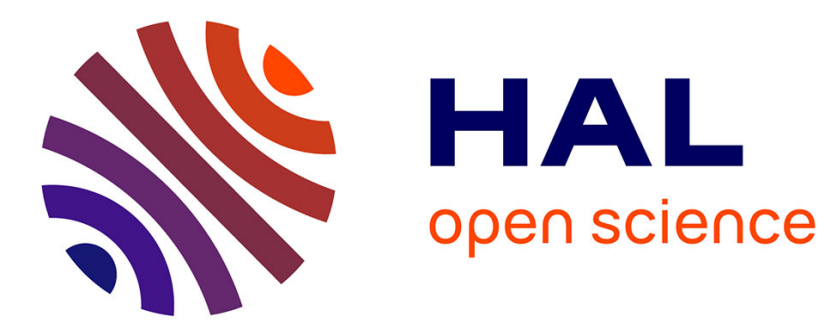

\title{
Atom Probe Field Ion Microscopy of High-Tc Superconductors
}

\author{
H.-O. Andrén
}

\section{To cite this version:}

H.-O. Andrén. Atom Probe Field Ion Microscopy of High-Tc Superconductors. Journal de Physique IV Proceedings, 1996, 06 (C5), pp.C5-197-C5-204. 10.1051/jp4:1996532 · jpa-00254411

\section{HAL Id: jpa-00254411 https://hal.science/jpa-00254411}

Submitted on 1 Jan 1996

HAL is a multi-disciplinary open access archive for the deposit and dissemination of scientific research documents, whether they are published or not. The documents may come from teaching and research institutions in France or abroad, or from public or private research centers.
L'archive ouverte pluridisciplinaire HAL, est destinée au dépôt et à la diffusion de documents scientifiques de niveau recherche, publiés ou non, émanant des établissements d'enseignement et de recherche français ou étrangers, des laboratoires publics ou privés. 
JOURNAL DE PHYSIQUE IV

Colloque C5, supplément au Journal de Physique III, Volume 6, septembre 1996

\title{
Atom Probe Field Ion Microscopy of High-T $\mathbf{T}_{c}$ Superconductors
}

\author{
H.-O. Andrén \\ Department of Physics, Chalmers University of Technology, 41296 Göteborg, Sweden
}

\begin{abstract}
This paper aims at reviewing the progress within APFIM of high- $\mathrm{T}_{\mathrm{c}}$ superconductors during the past ten years. Most of the studies has dealt with the compound $\mathrm{YBa}_{2} \mathrm{Cu}_{3} \mathrm{O}_{(6+\delta)}(\mathrm{YBCO})$, but many other compounds have also been investigated. The development of methods for specimen preparation, FIM imaging and APFIM analysis is described, and studies of interfaces and oxygen ordering are reviewed.
\end{abstract}

\section{INTRODUCTION}

\subsection{High- $T_{c}$ superconductors}

After a systematic search for superconductivity in oxides, J. G. Bednorz and K. A. Müller at IBM's Zürich Research Laboratory discovered a superconducting La-Ba-Cu-O compound in January 1986 [1]. Its critical temperature $T_{c}$ was $35 \mathrm{~K}$, much higher than the previous record of $23.3 \mathrm{~K}$ obtained already in 1973 with an intermetallic compound, $\mathrm{Nb}_{3} \mathrm{Ge}$. This surprising result immediately triggered a large research activity world-wide. Other oxides with a structure also related to the perovskite structure were immediately studied, and $\mathrm{La}-\mathrm{Sr}-\mathrm{Cu}-\mathrm{O}$ compounds gave ever increasing $\mathrm{T}_{\mathrm{c}}$ during 1986 [1]. Already in February 1987, a $\mathrm{T}_{\mathrm{c}}$ of $92 \mathrm{~K}$ was measured in a $\mathrm{Y}-\mathrm{Ba}-\mathrm{Cu}-\mathrm{O}$ compound, $\mathrm{YBa}_{2} \mathrm{Cu}_{3} \mathrm{O}_{(6+\delta)}$ ("YBCO", often also designated as $\left.\mathrm{YBa}_{2} \mathrm{Cu}_{3} \mathrm{O}_{(7-\mathrm{x})}\right)$ [2]. This compound has since been very extensively studied; its $\mathrm{T}_{\mathrm{c}}$ varies with oxygen stoichiometry from about 60 to about $90 \mathrm{~K}$ when $\delta$ varies from 0.5 to 0.9 . During the ten years that have passed after the first discovery of a ceramic superconductor, several hundred "high- $\mathrm{T}_{\mathbf{c}}$ " superconductors have been found, and at present the highest critical temperature recorded is $134 \mathrm{~K}$ in a $\mathrm{Hg}-\mathrm{Ba}-\mathrm{Ca}-\mathrm{Cu}-\mathrm{O}$ compound [3]. A still higher $\mathrm{T}_{\mathrm{c}}(156 \mathrm{~K})$ has been measured under high pressure [4].

\subsection{FIM and APFIM of superconductors}

This spectacular development within the field of superconductivity inspired a large activity in many branches of materials science, and atom probe field ion microscopy (APFIM) was no exception. Within a year after the discovery of YBCO field ion microscopy (FIM) and APFIM had been applied to this new class of materials by the research groups at Tokyo Institute of Technology [5], Sandia National Laboratories [6, 7, 8], Oxford [9], and National Bureau of Standards [10, 11]. At the 1988 International Field Emission Symposium (IFES) 8 papers dealing with high- $\mathrm{T}_{\mathfrak{c}}$ materials were presented; 11 more followed at the annual IFES Symposia during the years 1989-1992. This paper aims at reviewing the progress within APFIM of high- $T_{c}$ superconductors during the past ten years. Many of the studies have dealt with YBCO, but a large number of other high- $\mathrm{T}_{\mathrm{c}}$ superconductors has also been studied.

\section{SPECIMEN PREPARATION}

Needle-shaped FIM specimens of high- $\mathrm{T}_{\mathrm{c}}$ materials have been prepared by two main methods: electropolishing and mechanical fragmentation. 


\subsection{Electropolishing}

Several authors have used the standard method of cutting rod-shaped blanks and electropolishing them in a solution of perchloric acid in ethylene glycol monobutyl ether [6, 9, 12]; Zaharchuk et al. used the same electrolyte and the suspended droplet technique [13]. Hu and Alarco developed a method to electropolish at a temperature of $-35^{\circ} \mathrm{C}$ in a non-acid bath containing $\mathrm{LiCl}, \mathrm{Mg}\left(\mathrm{ClO}_{4}\right)_{2}$, butylcellosolve and methanol. This method gave a very good specimen surface (Figure 1) and no grain boundary attack [14].

\subsection{Mechanical fragmentation}

Mechanical means of specimen preparation have also been used $[5,10]$. To avoid any possible artefacts due to eletropolishing Melmed [15] produced fragments of the material by crushing, and attached sharplypointed fragments to a blunt point with electrically conductive adhesive, using a micromanipulator and an optical microscope. One advantage with this method is that thin superconducting films [16] and bulk materials having a high porosity may be studied; a disadvantage, however, is that often the fragments are not symmetric around their axes, which gives rise to elliptical distortion in the FIM image [17]. Leisch et al. used the fragmentation method to prepare specimens from a single crystalline YBCO material and found that if "green phase", orthorhombic $\mathrm{Y}_{2} \mathrm{BaCuO}_{5}$, was present in the crystal, fracture preferentially occurred through this phase, producing a surface layer of green phase some 10 to 20 atomic layers in depth [18].

\subsection{Surface layer composition}

The properties of the superconducting materials are often sensitive to the exact oxygen stoichiometry, and one important question is then how the normal techniques used to prepare needle-shaped specimens affect the oxygen content. Elswijk, Camus and Melmed addressed this problem in an APFIM study of $\mathrm{EuBa}_{2} \mathrm{Cu}_{3} \mathrm{O}_{6+\delta}$ and found that an oxygen-deficient layer, rich in Eu and $\mathrm{Ba}$, forms during normal preparation and acts as a diffusion barrier for further out-diffusion of oxygen for at least $80 \mathrm{~h}$ at room temperature.

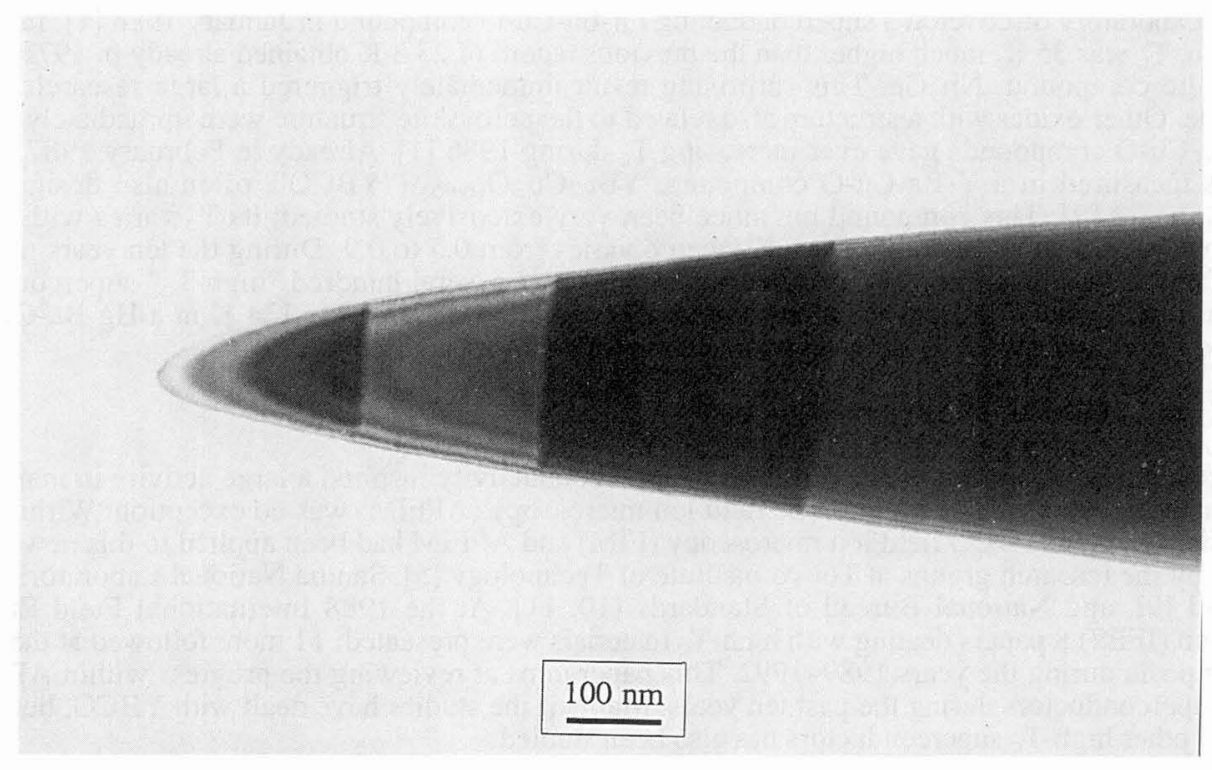

Figure 1: Transmission electron micrograph of a YBCO specimen, prepared by electropolishing. Note the twinned structure. (Courtesy Dr. Q.-H. Hu.) 
However, a field evaporated specimen with stoichiometric composition at the surface cannot be left in vacuum at room temperature without a considerable loss of oxygen. Fortunately, there is no loss of oxygen during a vacuum exposure of $3 \mathrm{~h}$ when the specimen is cryogenically cooled to $85 \mathrm{~K}[19,20]$. Cerezo et al. found a thin $\mathrm{Ba}$ enriched layer at the surface of an annealed $\mathrm{YBCO}$ specimen $\left(1 \mathrm{~h}\right.$ at $450^{\circ} \mathrm{C}$ in vacuum) and a depletion of $\mathrm{Ba}$ for about $1 \mathrm{~nm}$ below this layer, but very little effect on the oxygen stoichiometry [9]. Application of a negative field to YBCO, of sufficient strength to cause field electron emission, had the effect of depleting the surface of $\mathrm{Ba}$ and $\mathrm{O}$, which was interpreted as a field-assisted diffusion of these species to the specimen surface and subsequent evaporation [21]. No effect of a positive field was noted, however.

\subsection{Porosity}

One difficulty with APFIM of high- $T_{\mathfrak{C}}$ superconductors is their often high porosity, which is of minor concern for most other investigations but detrimental for APFIM analysis. Hu et al. had to develop methods to synthesise YBCO materials of high density in order to get suitable starting materials for APFIM specimen preparation [22].

\section{FIELD ION MICROSCOPY}

\subsection{Choice of image gas}

Initially a variety of image gases were tried for field ion microscopy of high- $T_{c}$ materials. Among the traditional gases $\mathrm{H}_{2}, \mathrm{Ne}, \mathrm{Ar}$, and $\mathrm{Xe}$, hydrogen at a low temperature generally gave the best result, although the image was often only marginally stable. Argon (at temperature above the boiling point $88 \mathrm{~K}$ to prevent condensation) usually gave better results than neon $[23,24,25]$. Russian researchers pioneered the use of nitrogen gas as image gas, which was found to give good images at about $70 \mathrm{~K}[12,26]$. Figure 2 shows an example of a YBCO specimen imaged with nitrogen gas at about $80 \mathrm{~K}$. Melmed et al. later used a mixture of $90 \% \mathrm{~N}_{2}$ and $10 \% \mathrm{H}_{2}[16]$.

\subsection{Image interpretation}

The most striking feature of FIM images of high- $\mathrm{T}_{\mathrm{c}}$ materials is the presence of "stripes", parallel rows of atoms, and the low number of visible poles [10, 16, 23, 24]. Melmed and co-workers studied a large number of compounds similar to YBCO $\left(\mathrm{RBa}_{2} \mathrm{Cu}_{3} \mathrm{O}_{6+\delta}\right.$, with $\mathrm{R}=\mathrm{Y}, \mathrm{Yb}, \mathrm{Sm}, \mathrm{Gd}, \mathrm{Dy}, \mathrm{Er}, \mathrm{Eu}, \mathrm{Ho}$ or $\left.\mathrm{La}\right)$, as well as $\mathrm{Tl}_{2} \mathrm{Ba}_{2} \mathrm{Ca}_{2} \mathrm{Cu}_{3} \mathrm{O}_{\mathrm{x}}, \mathrm{Bi}_{2} \mathrm{Sr}_{2} \mathrm{Ca}_{2} \mathrm{Cu}_{2} \mathrm{O}_{\mathrm{x}}$ and other BSCCO-type materials, and all of these materials showed the same FIM image features $[16,23]$. FIM images from non-superconducting (tetragonal) YBCO also exhibited the same kind of stripes [27]. All of the $\mathrm{RBa}_{2} \mathrm{Cu}_{3} \mathrm{O}_{6+\delta}$ superconducting materials have a layered orthorhombic structure, with the $c$-axis about three times larger than $a$ and $b$, and it was soon found that the stripes were the image of planes perpendicular to the c-axis and having the same distance as the $c$ axis lattice parameter [10]. However, the question of what part of the layered structure that gave contrast in the image was more difficult to answer. Image simulation of YBCO showed that only the Y containing layer or the $\mathrm{Cu}-\mathrm{O}$ "end planes" could give the observed contrast $[10,12,28]$. While Melmed et al. favoured the interpretation that the $\mathrm{Cu}-\mathrm{O}$ planes were imaging [10], Mesyats et al. by considering the twin boundary appearance concluded that $Y$ was the imaging species [12].

\section{ATOM PROBE ANALYSIS}

\subsection{Interpretation of spectra}

Due to the formation of numerous molecular ions, APFIM spectra from YBCO are complex with up to 50 peaks to consider (Figure 3). Analysis of YBCO at $80 \mathrm{~K}$ using electrical pulsing gave the following major peaks: $\mathrm{Y}^{2+}, \mathrm{Y}^{3+}, \mathrm{Ba}^{2+}, \mathrm{Cu}^{+}, \mathrm{Cu}^{2+}, \mathrm{O}^{+} ; \mathrm{YO}^{2+}, \mathrm{CuO}^{+}, \mathrm{CuO}^{2+}$ and $\mathrm{O}_{2}^{+}[7,9]$. Hydrides of many of these ions are also observed: $\mathrm{Cu}$ and $\mathrm{Y}$ (but not $\mathrm{Ba}$ ) form hydrides and hydroxide ions [29], and also the mixed $\mathrm{YCuO}^{2+}[5]$. Hydride formation complicates e.g. the separation of $\mathrm{Cu}^{2+}$ from $\mathrm{O}_{2}^{+}$, since $\mathrm{CuH}^{2+}$ overlaps $\mathrm{O}_{2}{ }^{+}$[7]. Minor peaks of $\mathrm{YOH}_{2}{ }^{3+}$ and $\mathrm{YCuH}^{3+}$ as well as $\mathrm{CuOH}^{+}$and $\mathrm{CuOH}_{3}{ }^{+}$have also been found [29]. Still more peaks are produced at the higher temperature and lower field present during laser pulsing. Nishikawa and Nagai [5] and Tsong et al. [30] found e.g. a number of molecular ions of $\mathrm{Ba}$ and $\mathrm{O}$ as well as of $\mathrm{Y}, \mathrm{Cu}$ and $\mathrm{O}$. 


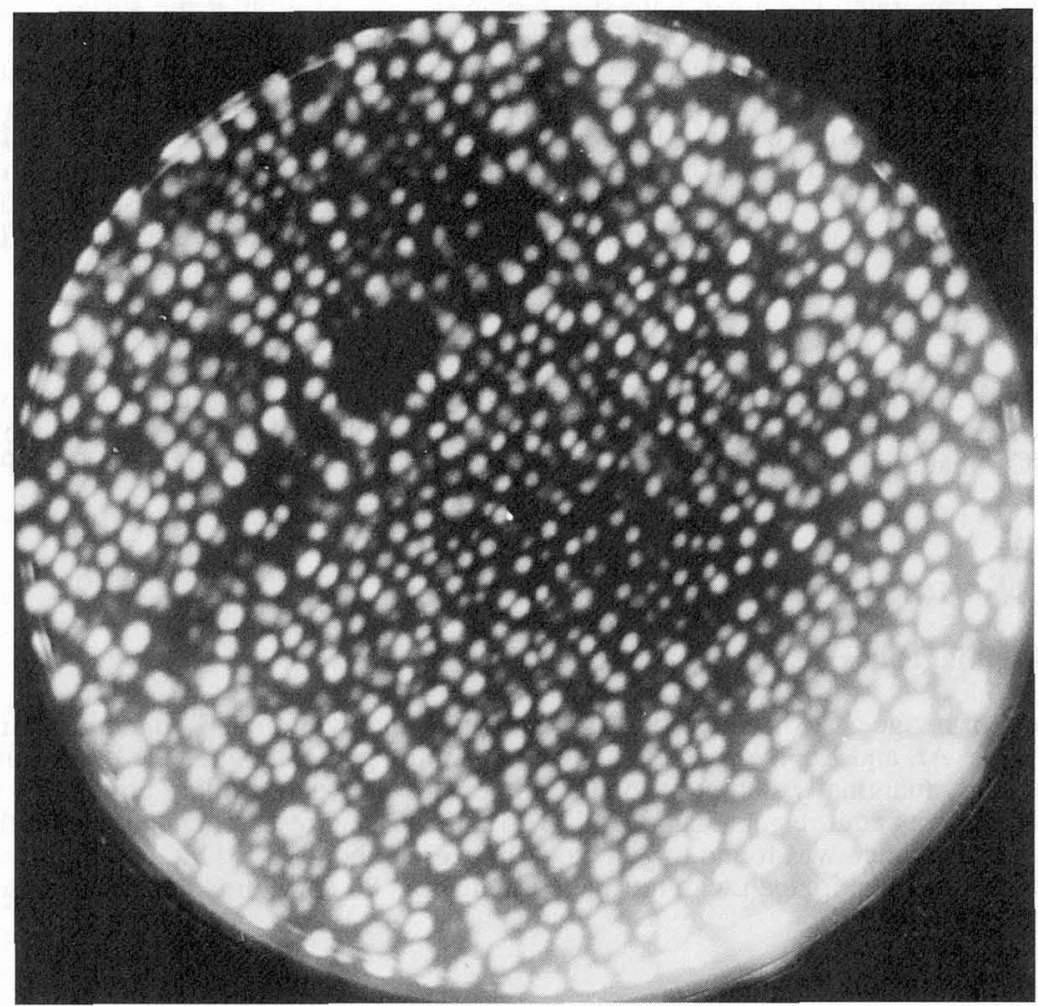

Figure 2: FIM image of a YBCO specimen, obtained at $80 \mathrm{~K}$ using nitrogen gas as image gas. Note the characteristic parallel rows of atoms and chain of poles. (Courtesy Dr. Q.-H. Hu.)

\subsection{Conditions for analysis}

Cerezo et al. [9] analysed YBCO with APFIM at $80 \mathrm{~K}$ and varying pulse fraction and concluded that 20\% pulse fraction was optimum for quantitative analysis. Zaharchuck et al. [13] obtained the best results at 160 $\mathrm{K}$ using $20 \%$ pulses. Hu et al. [29] varied both temperature and pulse fraction and found the best condition to be $40 \mathrm{~K}$ and $15 \%$ pulse. There was still a small systematic error with too low $\mathrm{Cu}$ and $\mathrm{O}$ content compared to chemical analysis.

\section{STUDIES OF INTERFACES}

\subsection{Twin and grain boundaries}

An undesired property of high- $T_{c}$ superconductors is their low critical current compared to the old type of superconductors. This is presumably connected to their much smaller coherence length and therefore higher sensitivity to the presence of "weak links" such as grain and twin boundaries. YBCO-type materials undergo extensive twinning when transforming from tetragonal to orthorhombic structure during fabrication, so twin boundaries are often observed with FIM. Twin and grain boundaries in YBCO have been observed in the FIM [16, 24, 31]. van Bakel et al. found that the visibility of a twin boundary was much better than predicted from a corresponding simulated FIM image of an unrelaxed twin boundary, and suggest that this was due to regional structural or compositional disordering [31]. Hu et al. [32] managed to analyse two twin boundaries in YBCO with APFIM. In oxygen deficient material $(\delta=0.6)$ a 6 to $7 \mathrm{~nm}$ wide region was found depleted of oxygen and with some Ba enrichment (Figure 4), whereas no depletion or enrichment 

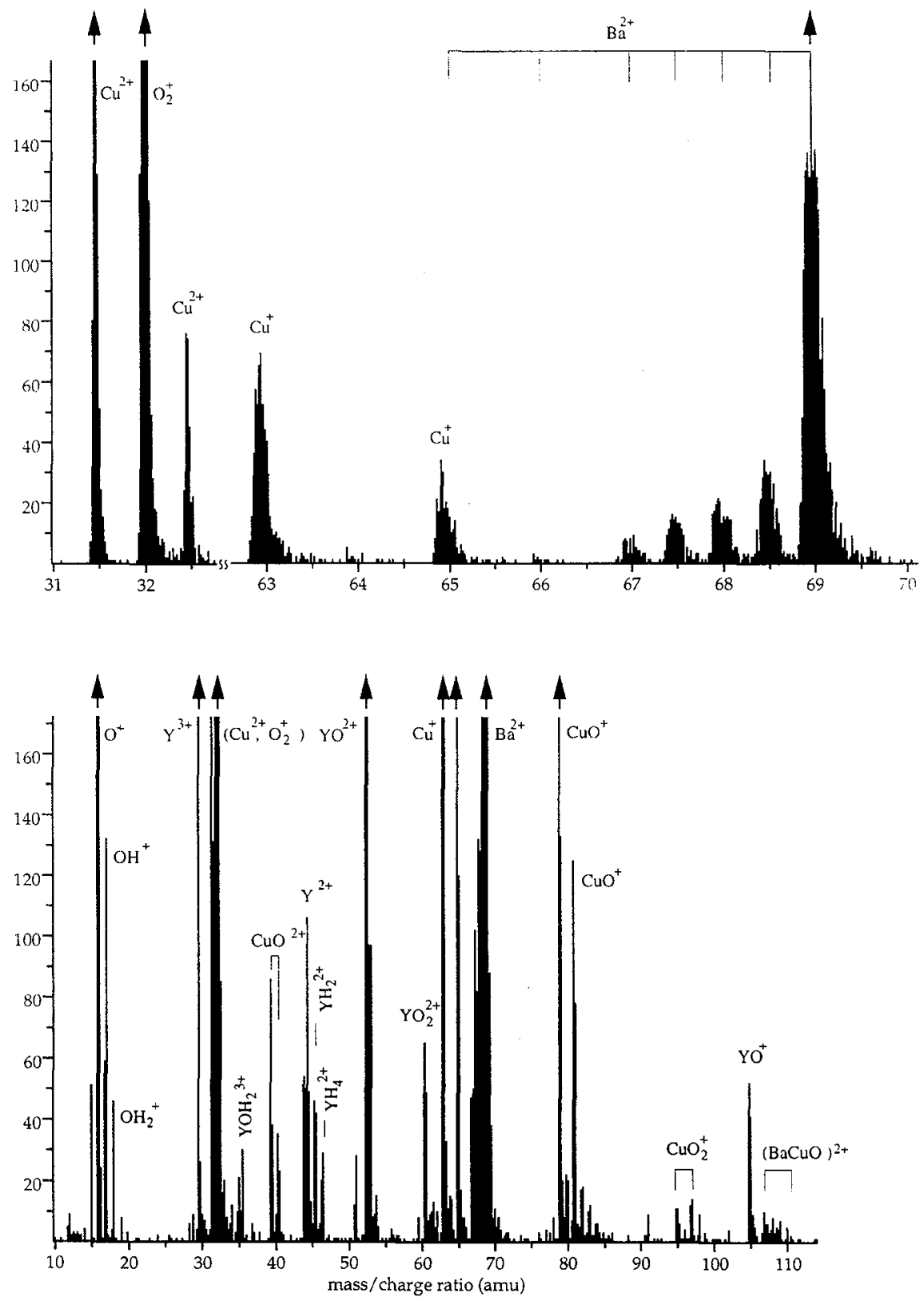

Figure 3: APFIM spectrum of a $\mathrm{YBa}_{2} \mathrm{Cu}_{3} \mathrm{O}_{6.9}$ specimen, obtained with an energy-compensated instument at $27 \mathrm{~K}$ and using $15 \%$ pulse fraction. The upper diagram is a magnification of the lower spectrum. Note the high occurrence of various molecular ions. (Courtesy Dr. Q.-H. Hu.) 


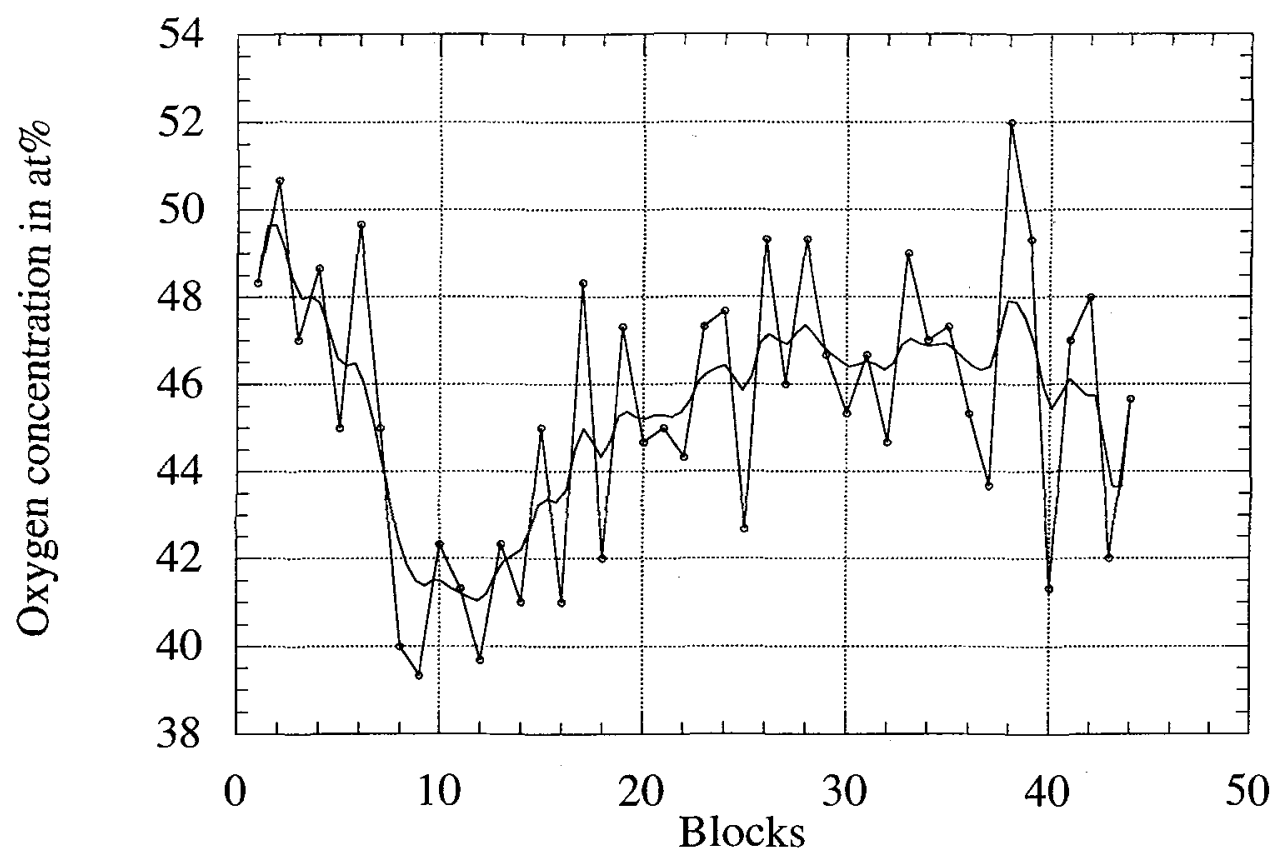

Figure 4: APFIM concentration profile through a twin boundary in a $\mathrm{YBa}_{2} \mathrm{Cu}_{3} \mathrm{O}_{6.6}$ specimen, obtained at $80 \mathrm{~K}$ and $15 \%$ pulse fraction. The curve without symbols is smoothened (running mean over 3 blocks). One block consists of 300 ions and corresponds to $0.85 \mathrm{~nm}$, so the oxygen depleted zone was 6 to $7 \mathrm{~nm}$ wide. (Courtesy Dr. Q. H. Hu.)

was found in a fully oxygenated $(\delta=0.9)$ material. The oxygen deficient material was prepared by heat treatment of a fully oxygenated sample in a flow of nitrogen gas, and the oxygen depleted region had probably formed during heat treatment due to oxygen out-diffusion through the twin boundary. This result is in accordance with that of van Bakel et al. and shows that twin boundaries may have disturbed oxygen ordering, which certainly would lead to a "weak-link" behaviour.

\subsection{Metal-superconductor interfaces}

Hoyle studied interfaces between various metals and YBCO, prepared by metal evaporation onto field evaporated specimens [33]. The adhesion of Au layer was poor, indicating a sharp interface, and an abrupt interface was also found for $\mathrm{Ag}$, whereas $\mathrm{Sn}$ and $\mathrm{Al}$ gave intermixing, in the case of $\mathrm{Al}$ leading to the formation of a thin layer of aluminium oxide.

\section{STUDIES OF ORDERING}

Changes in the oxygen content of YBCO changes the critical temperature $T_{c}$, and it has been shown by neutron diffraction that variation in oxygen stoichiometry is associated with the occupancy of oxygen in the $\mathrm{Cu}-\mathrm{O}$ chains in the basal plane [34]. Domains with different oxygen ordering is expected to form with different basal plane configuration ("ortho-I", $\delta=1$, and "ortho-II" $\delta=0.5$ ), but the size of the domains is expected to be small and attempts to measure their size and composition with diffraction techniques or conventional microanalytical instruments have as yet not been successful. $\mathrm{Hu}$ et al. [35] attempted to use APFIM and statistical analysis to measure oxygen ordering in YBCO materials with different oxygen contents. Between 40000 and 80000 ions were collected from random area analysis of YBCO materials with different oxygen stoichiometries, corresponding to a volume of typically $100 \mathrm{~nm}$ length and $2-5 \mathrm{~nm}$ diame- 
ter. The data chain was divided into blocks, and the frequency distribution for oxygen concentration were calculated. For or certain block sizes in materials with $\delta=0.6,0.7$ and 0.9 , two peaks in the frequency distribution appear to indicate nanometer-scale oxygen ordering, and the oxygen content in the two types of domains corresponded to $\delta=0$ and $\delta=1$. No ordering could be observed in a $\delta=0.5$ material. However, the domain size is very small and the expected difference in oxygen concentration between domain types is only a few per cent, so also APFIM analysis has difficulties in detecting the ordering. At present several different types of simulations are being made to test the significance of the results.

\section{CONCLUSIONS}

The APFIM community responded quickly to the discovery of high- $T_{c}$ superconductors, and during a few years methods of specimen preparation, FIM imaging and APFIM analysis were successfully developed. The applications of APFIM to problems relevant for the superconducting community have as yet been rather few, though, probably due to the complexity of the materials and many practical problems that arise when studying these materials on a routine basis. Unique information regarding interfaces and ordering has so far been the main contribution from FIM and APFIM to the understanding of these fascinating materials.

\section{Acknowledgements}

This paper is partly based on Q.-H. Hu's PhD Thesis "APFIM of Electronic Materials" (Chalmers University 1995). Support from the Swedish Research Council for Engineering Sciences is gratefully acknowledged.

\section{References}

[1] Bednorz J.G. and Müller, K.A., Angew. Chem. 100 (1988) 757-770 (Nobel Lecture).

[2] Wu M.K., Ashburn J.R., Torng C.J, Hor P.H., Meng R.L., Goa L., Huang Z.J., Wang Y.Q. and Chu C.W., Phys. Rev. Lett. 58 (1987) 908-911.

[3] Schilling A., Cantoni M., Guo J.D. and Ott H.R., Nature 363 (1993) 56.

[4] Chu C.W., Gao L., Chen F., Huang Z.J., Meng R.L. and Xue Y.Y., Nature 365 (1993) 323

[5] Nishikawa O. and Nagai M., Phys. Rev. B37 (1988) 3685-3688.

[6] Kellogg G.L. and Brenner S.S., Appl. Phys. Lett. 51 (1987) 1851-1853.

[7] Brenner S.S. and Kellog G.L., in "High Temperature Superconductors", M.B. Brodsky, R.C. Dynes, K. Kitazawaand H.L. Tuller Eds., Mat. Res. Soc. Symp. Proc. 99 (1988) 947-950.

[8] Kellogg G.L. and Brenner S.S., in "Thin Film Processing and Characterization of High-Temperature Superconductors", J.M.E. Harper, R.J. Colton and L.C. Feldman, Eds., Am. Inst. Phys. Conf. Proc. 165 (1988) 421-426.

[9] Cerezo A., Grovenor C.R.M., Hoyle R.M. and Smith G.D.W, Appl. Phys. Lett. 52 (1988) 10201022.

[10] Melmed A.J., Shull R.D., Chiang C.K. and Fowler H.A., Science 239 (1988) 176-178.

[11] Melmed A.J., Shull R.D., Chiang C.K. and Fowler H.A., Mater. Sci. Eng. 100 (1988) L27.

[12] Mesyats G.A., Syutkin N.N., Ivchenko V.A. and Talantsev E.F., J. de Physique 49 (1988) C6-477481.

[13] Zaharchuck G., v. Alvenseben L., Oehring M. and Haasen P., J. de Physique 49 (1988) C6-471476.

[14] Hu Q.-H. and Alarco J.A., Surf. Sci. 266 (1992) 538-544.

[15] Melmed A.J., J. de Physique 49 (1988) C6-67-71.

[16] Melmed A.J., Camus P.P., Vargas J. and Larbalestier D.C., Appl. Surf. Sci. 67 (1993) 413-418.

[17] Elswijk H.B., Melmed A.J. and Fowler H.A., J. de Physique 49 (1988) C6-489-493.

[18] Leisch M., Eisl M., Schweiger E. and Leising G., J. de Physique 50 (1989) 481-486.

[19] Elswijk H.B., Melmed A.J. and Camus P.P., Appl. Phys. Lett. 55 (1989) 2667-2669.

[20] Camus P.P., Elswijk H.B. and Melmed A.J., J. de Physique 50 (1989) C8-477-480.

[21] Melmed A.J., Camus P.P., Ernst N., Schmidt W.A., Bozdech G. and Naschitzki M., Surf. Sci. 246 (1991) 173-176.

[22] Hu Q.-H., Stiller K., Olsson E., Andrén H.-O., Berastegui P. and Johansson G., Physica C 235240 (1994) 431-432.

[23] Melmed A.J., Shull R.D. and Chiang C.K., J. de Physique 49 (1988) C6-459-464.

[24] Miller M.K., Melmed A.J. and More K.L., J. de Physique 49 (1988) C6-447-452.

[25] Kellogg G.L. and Brenner S.S., J. de Physique 49 (1988) C6-465-470. 
[26] Talantsev E.F., Ivchenko V.A., Syutkin N.N., Samokhvalov A.A. and Chebotaev N.M., Sverkhprovodimost: Fizika, Khimiya, Tekhnika 2 (1989) 123-130.

[27] Kellogg G.L. and Brenner S.S., Appl. Phys. A48 (1989) 197-201.

[28] Miller M.K. and More K.L., J. de Physique 491988 C6-483-488.

[29] Hu Q.-H., Stiller K., Andrén H.-O., Appl. Surf. Sci. 67 (1993) 419-423.

[30] Tsong T.T., Chen C. and Liu J., J. Mater. Res. 4 (1989) 1549.

[31] van Bakel G.P.E.M., Hof P.A., van Engelen J.P.M., Bronsveld P.M. and De Hosson J.T.M., Phys Rev. B41 (1990) 9502-9505.

[32] Hu Q.-H., Stiller K., Olsson E., Andrén H.-O., Berstuegui P. and Johansson L.-G., submitted to Physica $C$

[33] Hoyle R.M., "Atom probe studies of superconducting materials". Final year project Thesis (Chemistry Part II), Univ. of Oxford (1988).

[34] Jorgensen J.D., Beno M.A., Hinks D.G., Soderholm L., Volin K.J., Hitterman R.L., Grace J.D. and Schuller I.K., Phys Rev. B36 (1987) 3608.

[35] Hu Q.-H., Thuvander M., Stiller K., Olsson E., Andrén H.-O., Berstuegui P. and Johansson L.-G., to be submitted to Phys. Rev. B 